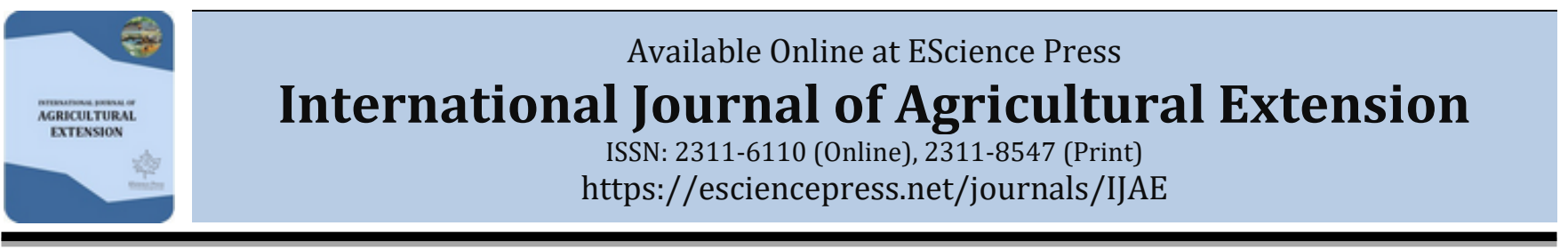

\title{
DEMONSTRATION AND POPULARIZATION OF PROCESSING, POST-HARVEST HANDLING AND UTILIZATION OF CASSAVA FOOD PRODUCTS IN SEMEN ARI WOREDA OF SOUTH OMO ZONE, SNNPR
}

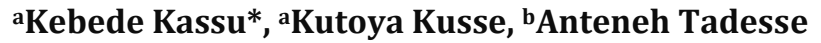 \\ a Southern Agricultural Research Institute, Jinka Agricultural Research Center, Socio-Economics Research, Technology \\ Transfer and Multiplication Directorate; Agricultural Extension Researcher and Socio Economics Researcher, Jinka, \\ Ethiopia. \\ ${ }^{b}$ Southern Agricultural Research Institute, Jinka Agricultural Research Center, Crop Science Research Directorate; Food \\ science and post-harvest handling researcher, Jinka, Ethiopia.
}

*Corresponding Author Email: kebedekassu@gmail.com

\section{A B S T R A C T}

This study aimed to demonstrate and popularize new value-added products of cassava and to provide improved techniques of processing cassava on rural households' levels in major cassava growing areas of Semen Ari Woreda. From the Woreda two clusters, Arfaro and Mellorasha were selected by using purposive sampling technique. Training manual was developed and Practical training on processing, post-harvest handling, and utilization of cassava flour were given for 20 DAs, 18 Administrators and 181 model Farmers comprising of 121 female farmers and 60 model male farmers. From each cluster 5 kebeles and a total of 10 Kebeles were selected. 30 model respondent farmer households were interviewed about the technology in which 20 are females and 10 are male farmers among 181 total farmers participated in the training. Recipe and Sensory evaluation tests and other relevant data were; collected, analyzed, interpreted, and discussed. Post-harvest handling technology of cassava was about $80 \%$ excellent, $13.33 \%$ very good and $6.67 \%$ good; since the humidity in the study area was very low the product cassava tuber is chopped with a knife in large pieces which were not easily dried with a short period of time, rather it was exposed to perishability. Farmers ranked the preference criteria; Post-harvest handling of technology, Value addition, Processing of technology and Balanced diet as first, second, third and fourth respectively. Farmers preferred cassava Borde, flour, and fossose as first, second and third rank respectively.

Keywords: Processing, Cassava Flour, Postharvest Handling, Utilization, Recipe Making, Demonstration, Technology.

\section{INTRODUCTION}

Cassava (Manihot esculenta Crantz) is the fourth most important crop for farmers in tropics after rice, wheat and sugar, consumed by up to a billion people globally (FAOSTAT, 2010). Cassava (Manihot esculenta Crantz) is a perennial woody shrub with an edible root, which grows in tropical and subtropical areas over the world. Cassava originated from tropical America and was first introduced into Africa continent in the Congo Basin by the Portuguese around 1558. Cassava root production has been increasing steadily since the 1960s but between 1997 and 2007 its production increased by over $40 \%$ (from 161 to 224 million tonnes), and its use in animal feed increased by 76 million tonnes (FAO,
2014). However, the nutrient composition of cassava differs according to the variety and age of the harvested crop, and soil conditions, climate, and other environmental factors during the cultivation of cassava. Ethiopia with its diverse agro-ecological zones and suitable environments allows the growth of numerous root and tuber crops in many parts of the country on the farmland of smallholder farmers. Cassava (Manihot esculenta Crantz) plant is exotically was introduced to Ethiopia in the middle of the nineteenth century (Desalegn, 2007).

The average total land coverage and production of cassava crop per annum in Southern regional state of Ethiopia is 195055 hectares with a yield of 501278.5 
tones indicating the average productivity of cassava in the country as a whole is not more than 25 ton per hectare (SNNPR, BoA, 2014), which is by far lower than that of the yield obtained by other tropical African countries such as Nigeria, 35.00 tons per hectare per year (FAOStat, 2013) Although its first introduction in to the country is not yet known, the crop had been growing in south, southwest and western part of Ethiopia for several years. It is used as one of the potential food crops in Ethiopia and has been appreciated since 1984 famine (Amsalu, 2006).

Cassava (Manihot esculenta Crantz) is grown by smallholder farmers in more than 100 tropical and subtropical countries of the world. Thanks to its efficient and wise use of water and soil nutrients, and tolerance to drought and sporadic pest attacks, cassava can produce reasonable yields in areas where it is produced, using few of any inputs, in areas with poor soils and unpredictable rainfall. The roots of cassava are very rich in carbohydrates, which makes them an important source of dietary energy. Producers can be consumed cassava as a fresh after cooking, processed into many food products, or fed to their livestock. Cassava root starch can be used in a wide array of industries, from food manufacturing and pharmaceuticals to production of plywood, paper, and bio-ethanol. In some countries of the world, cassava is also grown for its leaves, which contains up to $25 \%$ protein.

The global average yields have increased by almost $1.8 \%$ a year over the past decade, to 12.8 tons per hectare. With better crop and soil management, and cultivation of higher-yielding varieties, which are more resistant to drought, pests, and diseases, cassava could produce average root yields estimated at 23.2 tonnes (FAO, 2013). These conditions favor the easy development of storage pests and microbial contaminants such as Aspergillus flavors (aflatoxins) among others. Thus, a survey was conducted on five cassava growing areas of southern Ethiopia to document and transfer knowledge on current status, potentials and challenges on the cassava farming system of southern Ethiopia (Tadesse et al., 2013).

This activity is conducted to alleviate the problem of postharvest handling, utilization, and storage of cassava for a long time by processing cassava into the flour and other different cassava recipes (cassava chips, cassava dabokolo, cassava sambusa, cassava injera, cassava bread, etc). Therefore, the demonstration and popularization of a cassava food product are important for improving the nutritional status and additional income of the farmers.

\section{General Objective}

- To demonstrate and popularize new value-added products of cassava and to provide improved techniques of processing cassava at rural household level.

\section{Specific Objectives}

- To train model female and male farmers, DAs and small-scale enterprises on the preparation, postharvest handling and utilization of different recipes of cassava at rural household level.

- To taste different cassava food products for suitability to different recipe makings

\section{MATERIALS AND METHODS}

Description of the Area: Based on the 2007 Census conducted by the Central Statistical Agency, this woreda has a total population of 67,431 , of whom 33,367 are men and 34,064 women; 2,354 or $3.49 \%$ of its population are urban dwellers. The majority of the inhabitants were Protestants, with $51.7 \%$ of the population reporting that belief, 33.91\% practiced traditional beliefs, $7.23 \%$ practiced Ethiopian Orthodox Christianity, and $1.48 \%$ was Catholic (Census, 2007).

Semen Ari Woreda is located in South Omo Zone of the SNNP region. The administrative seat of the Woredais Gelila Town located $602 \mathrm{~km}$ southwest of the national capital. The Woreda is bounded by Basketo Special Woredaand Geze Gofa Woredain the north, Oyda, and Ubba-Debretsehay woredas in the east, and Debub Ari Woredain the southwest. The total land area of Semen Ari Woreda is 60,040 hectares. The Woredahas four agro-climatic zones: dega (50.28\%), woina dega (8.32), kolla (37.14) and wurch (4.26). The average annual rainfall and temperature in the Woreda vary between $400 \mathrm{~mm}$ and $2600 \mathrm{~mm}$, and $11^{\circ} \mathrm{c}$ and $22^{\circ} \mathrm{c}$ respectively. The altitude varies from 900 meters to 3,200 meters above sea level. The total population of the Woredais estimated to be 84,607 (male 41,457, female 43,150) Based on the information obtained from Semen Ari Woreda Agricultural Office. Agriculture is the main means of subsistence in Semen Ari Woreda. The main crops produced in the Woredainclude cereals (wheat, barley, sorghum, maize, teff, and millet), pulses (broad beans, beans, and peas), and root crops (taro, enset, yam, cassava, and potato). Coffee and cardamom are the two important cash crops produced in the Woreda. Also, 
livestock (cattle, sheep, goats, mules, horses, donkeys, and poultry) are raised. For administrative purposes, Ari land is divided into Semen (North) and Debub (South) Ari woredas. The woredas are mainly populated by Ari ethnic group who speak a language belonging to the Omotic language family. The Ari is the Omotic speaking group, following a language Araf. There are two occupational groups in Ari: the Kansa and the Manna. The Kansa practice agriculture and enjoy higher social status. The Manna, on the other hand, is an isolated and underserved social group. The Ari is generally in a peaceful relationship with their neighbors. Particularly, they maintain close marriage and trade relations with the Banna, Dime, Basketo, and Gofa. The Ari people trade coffee, cardamom, ginger and grains with these groups.
Site and Farmer Selection: The Demonstration was conducted in major cassava growing areas in Semen Ari woreda of South Omo Zone. Semen Ari was selected purposively based on the area allocated for cassava growing, number of cassava growers, accessibility and engagement in other research projects. Based on the above criteria10 Kebles from the Woreda were selected and also two FTCs were included. Firstly, Alfaro and Secondly, Melorasha FTCs were selected in which each had five kebeles. Following the site identification, selecting the participating farmers at all sites was done by selecting randomly 20 farmers per kebeles. Selections of the farmers were based primarily on farmer's land covered with cassava, production status and willingness to participate in the research.

Table 1. Cassava Flour Blend Formulation/Blending Ratio.

\begin{tabular}{lc}
\hline Type of product & Blend proportion \\
\hline Cassava flour & $100 \%$ cassava flour \\
Cassava Injera & $60 \%$ cassava flour $+40 \%$ tef flour \\
Cassava Bread & $60 \%$ cassava flour $+40 \%$ wheat flour \\
Cassava Anbasha & $60 \%$ cassava flour $+40 \%$ wheat flour \\
Cassava cookies & $60 \%$ cassava flour $+40 \%$ wheat flour \\
Cassava dabokollo & $60 \%$ cassava flour $+40 \%$ wheat flour \\
Cassava fosesie (a traditional local food) & $60 \%$ cassava flour $+40 \%$ maize flour \\
Cassava areke (a traditional local beverage) & $60 \%$ cassava flour $+40 \%$ maize flour \\
Cassava borde (a traditional local beverage) & $60 \%$ cassava flour $+40 \%$ maize flour \\
\hline
\end{tabular}

Technology demonstrated and recipe making of cassava technology: The Demonstration was undertaken to develop and popularize new value-added food products of cassava using the released variety namely kulle. Different composite flours from cassava and local cereals such as teff, wheat, maize, sorghum, and finger millet were prepared. Cassava flour and different food recipes cassava like cassava injera, cassava bread, cassava anbasha, cassava cookies, cassava dabokollo, traditional (local) foods like fossie (aybeza) and other traditional (local) beverages like arki (estrange) and borde mixed with cereals in different proportions and insole were prepared. Then their palatability was tested. Each product was packed in plastic bags and stored at room temperature for shelflife determination.

Training and Participants: Training manual was developed and Practical training on processing, postharvest handling, and utilization of cassava flour were imparted to 20 development agents, 18
Administrators and 181 model Farmers comprising of 121 female and 60 male farmers (Table 2).

Promotion: Promotional materials such as brochures and preparation guidelines were prepared and distributed to farmers for promoting awareness about cassava utilization. During the demonstration, the day was also prepared to farmers for promoting awareness about cassava utilization. Among 181 farmers 30 were interviewed from major cassava growing Kebeles of Semen Ari Woreda (Arfaro and Mellorasha FTCs) by simple random sampling. From the farmers, who were interviewed about the technology, 20 were females and 10 were male farmers. Data collected were analysed using Statistical Package for Social Sciences (SPSS Software version, 20).

\section{RESULTS AND DISCUSSION}

Sex of the Household: In most developing countries, women manage components of the cassava post-harvest handling system that contain a high level of biodiversity that can be used for daily culinary use (Admasu, 2002). 
Table 2. Participants of the farmers, development agents and administrators.

\begin{tabular}{lcccccccccc}
\hline Name of kebeles & \multicolumn{3}{c}{ DA } & \multicolumn{3}{c}{ Keble Administrator } & \multicolumn{3}{c}{ Farmers } \\
\cline { 2 - 10 } Wala & $\mathrm{M}$ & $\mathrm{F}$ & $\mathrm{T}$ & $\mathrm{M}$ & $\mathrm{F}$ & $\mathrm{T}$ & $\mathrm{M}$ & $\mathrm{F}$ & $\mathrm{T}$ & \\
\cline { 2 - 10 } Arifaro & 2 & 0 & 2 & 2 & 0 & 2 & 5 & 15 & 20 & 24 \\
Otela & 2 & 0 & 2 & 2 & 0 & 2 & 5 & 16 & 21 & 25 \\
Lelo & 2 & 0 & 2 & 2 & 0 & 2 & 4 & 12 & 16 & 20 \\
Sharadefti & 1 & 1 & 2 & 2 & 0 & 2 & 5 & 9 & 14 & 18 \\
Malorasha & 2 & 0 & 2 & 1 & 0 & 1 & 9 & 6 & 15 & 18 \\
Menorasha Sefera & 2 & 0 & 2 & 2 & 0 & 2 & 7 & 15 & 22 & 26 \\
Gama kora & 2 & 0 & 2 & 2 & 0 & 2 & 5 & 15 & 20 & 24 \\
Gomera & 2 & 0 & 2 & 2 & 0 & 2 & 5 & 15 & 20 & 24 \\
Gecha & 2 & 0 & 2 & 2 & 0 & 2 & 9 & 5 & 14 & 18 \\
& 2 & 0 & 2 & 1 & 0 & 1 & 6 & 13 & 19 & 21
\end{tabular}

Cross-Cutting Issues; Nutrition, Gender and ClimateSmart Agriculture (CSA) of the Technology Enhancing productivity of Cassava is very important to improve, income and Contribute to the local demand of the rapidly growing population. The beneficiaries of the project were small scale farmers and extension workers, NGOs, Researchers, etc, as shown in Table 3. About $33.3 \%$ respondents were male and $66.7 \%$ were females who participated in the demonstration of the cassava technology demonstration as females have a great role in the processing and utilization of the technology.
Table 3. Sex of the household.

\begin{tabular}{|c|c|c|c|}
\hline Sex & & Frequency & Percentage \\
\hline Male & & 10 & 33.3 \\
\hline Female & & 20 & 66.7 \\
\hline Total & & 30 & 100.0 \\
\hline \multicolumn{4}{|c|}{ Table 4. Age of the household. } \\
\hline Age & Minimum & Maximum & Mean age \\
\hline Male & 23 & 42 & 28 \\
\hline Female & 22 & 50 & 34.5 \\
\hline
\end{tabular}

Age of the Households: As shown in Table 4, among male participants, minimum age was 23 years and maximum of 42 with a mean of 28 years. While the female category of the respondents, had a minimum age of 22 and maximum of 50 with a mean of 34.5 years.

Table 5. Preference Selection criteria of the farmers comparison $b / n$ traditional "PHHPU" of Cassava with new technology.

\begin{tabular}{|c|c|c|c|c|c|c|c|}
\hline \multirow[t]{3}{*}{ Preference Criteria } & \multicolumn{6}{|c|}{ Level of preference } & \multirow{3}{*}{ Rank } \\
\hline & \multicolumn{2}{|c|}{ Excellent } & \multicolumn{2}{|c|}{ Very good } & \multicolumn{2}{|c|}{ Good } & \\
\hline & $F$ & $P$ & $\mathrm{~F}$ & $P$ & $F$ & $P$ & \\
\hline Postharvest handling of technology & 24 & 80 & 4 & 13.33 & 2 & 6.67 & $1^{\text {st }}$ \\
\hline Processing of technology & 21 & 70 & 7 & 23.33 & 2 & 6.67 & $3^{\text {rd }}$ \\
\hline Balanced diet & 19 & 63.33 & 6 & 20 & 5 & 16.67 & $4^{\text {th }}$ \\
\hline Value addition & 23 & 76.67 & 7 & 23.33 & - & - & $2^{\text {nd }}$ \\
\hline
\end{tabular}

$\mathrm{F}=$ frequency; $\mathrm{P}=$ percentage.

The above Table 3.2 shows that the respondent farmers preferred the criteria of new technology over the traditional practice. Post-harvest handling technology of cassava was about $80 \%$ excellent, $13.33 \%$ very good and $6.67 \%$ good; since the humidity in the study area was very low the product cassava tuber is chopped with a knife in large pieces which were not easily dried with a short period of time, rather it was exposed to perishability. Furthermore, farmers do not take care of harvesting and made injured. Because of these reasons, the new post-harvest handling of cassava decreased these listed problems by harvesting with care and chopping washed tuber with a pure knife in small pieces to be dried easily and timely. Also, it favors supplying to the market at the right time at a good price. The processing technology of cassava was about $70 \%$ excellent, $23.33 \%$ very good and $6.67 \%$ good. Farmers in the study area were chopping cassava tuber in traditional practice with large pieces and do not remove the pith inside of the tuber which decreases the quality 
of the flour, but the new processing developed this thread-like structure and the toxicity of the Hydrogen cyanide (HC) since released when exposed to sunlight. A balanced diet of the technology was about $63.33 \%$ excellent, $20 \%$ very good and $16.67 \%$ good; and also, value addition of the technology relative to the traditional practice was $76.67 \%$ excellent, $23.33 \%$ very. Farmers ranked the performance criteria; Postharvest handling of technology, Value addition, Processing of technology and Balanced diet as first, second, third and fourth respectively. Cassava serves as a source of food security against famine in the developing countries because of its long storage ability in the ground prior to harvest (El-Sharkawy, 2004). The root part of cassava can be processed into different food items for human consumption, animal feed and as industrial raw material for paper, textiles and also for alcoholic drinks (Haggblade et al., 2012). Cassava is utilized in many forms, but the utilization of cassava root for food and other industrial raw material applications is limited by the post-harvest handling physiological deterioration (PPD), which reduces the shelf life and degrades its quality attributes (Sánchez et al. 2006). The metabolic process continues after the harvest of cassava, resulting in softening and decay of the root and, thus, rendering it unwholesome for human consumption (Salcedo et al., 2010). Other factors that can cause deterioration of cassava root include pests, disease and mechanical damage such as cuts and bruises which occur during harvesting, postharvest handling, and processing of the product (Iyer et al., 2010).

Converting cassava root to other food items and forms creates products with longer shelf life, adds value to the root and reduces postharvest loses of the crop (Falade \& Akingbala, 2010). Furthermore, the application of safety postharvest handling techniques, processing, packaging, and storage techniques is one of the critical importance for successful large-scale production and utilization of cassava roots and its products. Successful application of these postharvest technologies will contribute towards maintaining product quality and safety as well as reducing the incidence of postharvest losses and, thereby, improve the food security of the poor farmers (Opara, 2013).

Cassava is one of the major tropical staple food crops alongside yam, plantain, and sweet potato, and it is considered as one of the good sources of carbohydrate and the fourth most energy-giving diet (Mudombi, 2010). Many cultivars are grown cassava, which can serve for different purposes; some of them are produced for human consumption, while others are for industrial inputs and animal feed (Falade \& Akingbala 2010). The demand for cassava crops has been increased most especially in developing countries of the world, where low supplies of cereals are experienced. This is because of its significant use for human consumption as food and beverage industries as composite flour (Eddy et al., 2012).

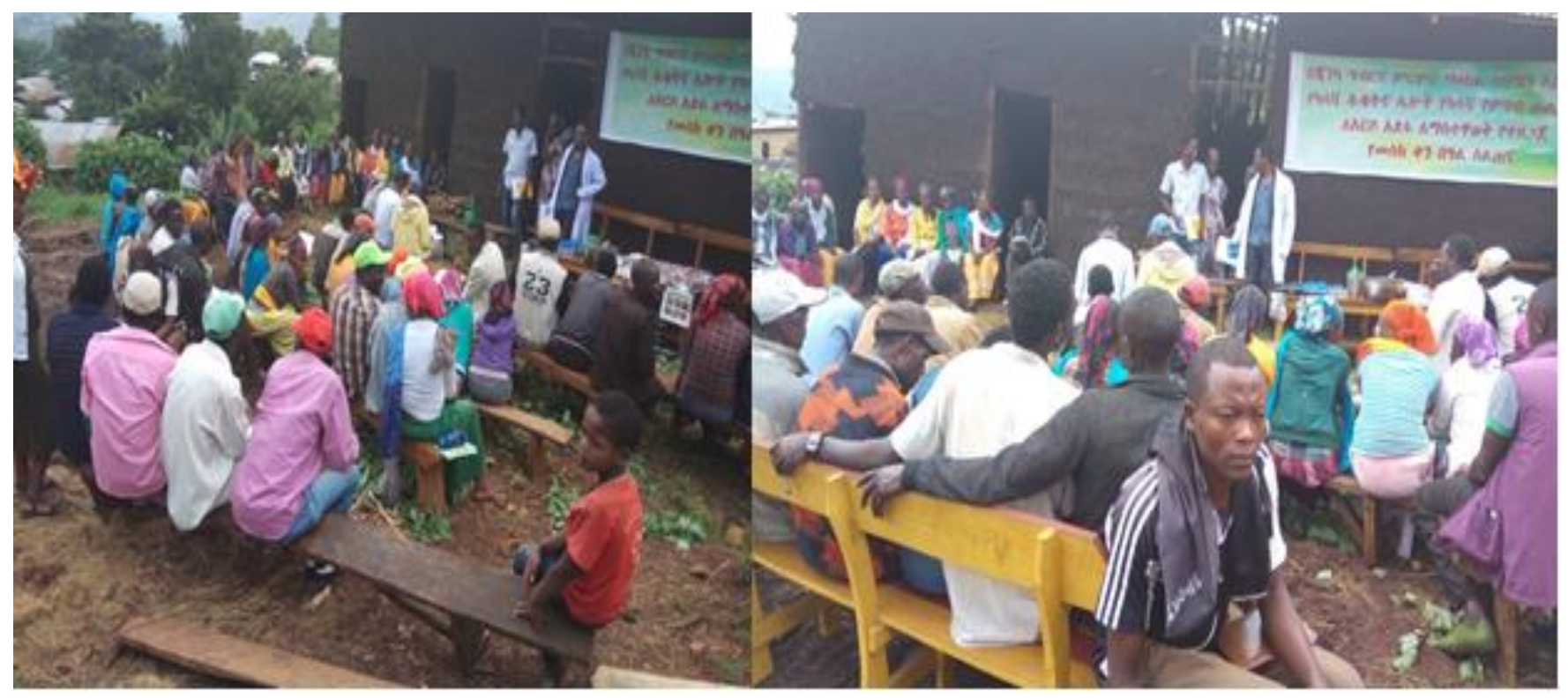

Figure 1. Farmers, Development Agents and Woreda Experts on training of processing, post-harvest handling of Casssava at Malorasha Cluster of Semen Ari Woreda. 


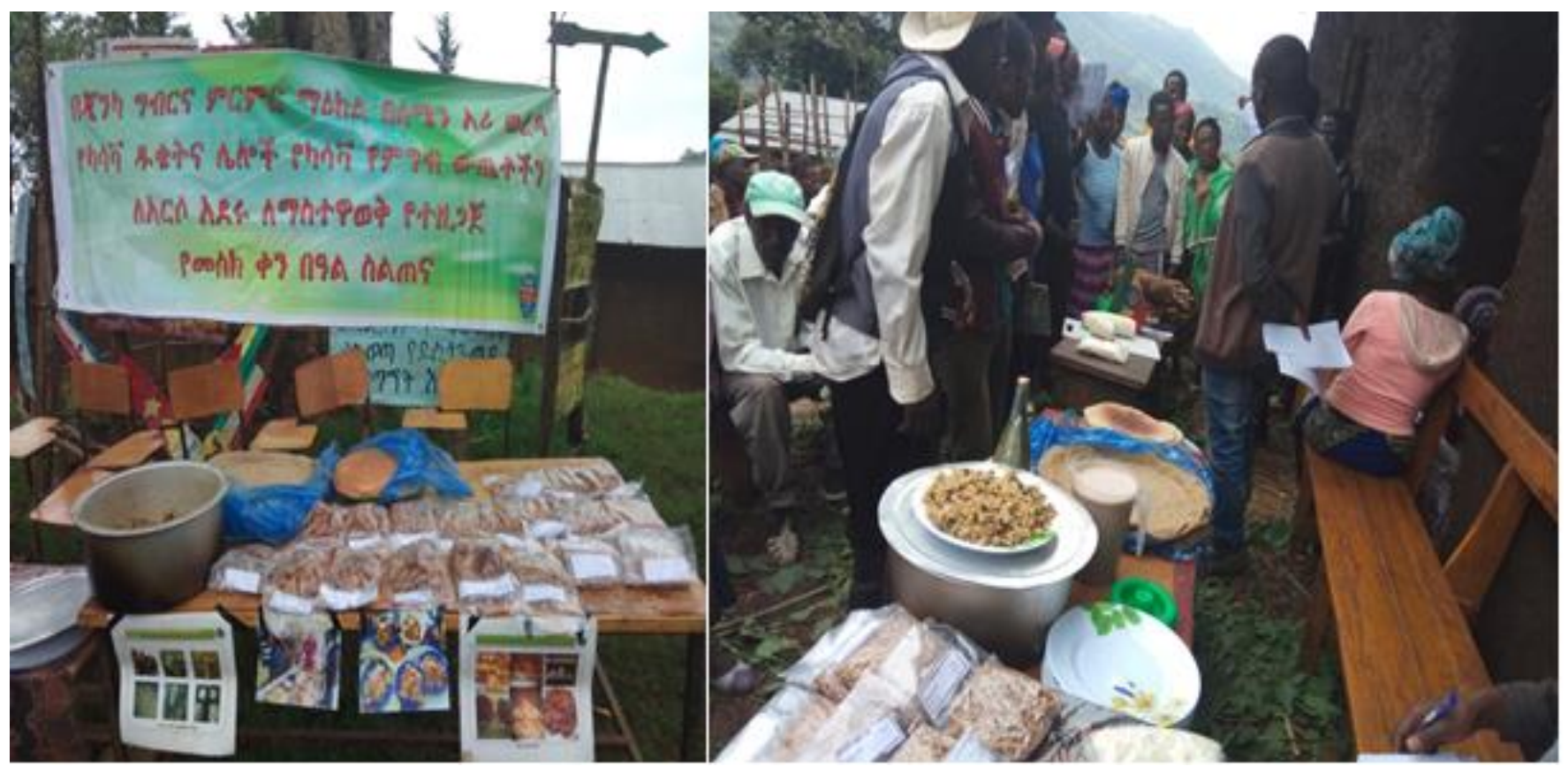

Figure 2. Cassava food products ready to utilize in Arifaro cluster of Semen Ari Woreda.

Table 6. Delicious foods preference among the cassava foods prepared.

\begin{tabular}{|c|c|c|c|c|c|c|c|c|c|c|}
\hline \multirow{2}{*}{ Food items } & & \multicolumn{9}{|c|}{ Preference Ranking } \\
\hline & & $1^{\text {st }}$ & $2^{\text {nd }}$ & $3^{\text {rd }}$ & $4^{\text {th }}$ & $5^{\text {th }}$ & $6^{\text {th }}$ & $7^{\text {th }}$ & $8^{\text {th }}$ & $9^{\text {th }}$ \\
\hline \multirow[t]{2}{*}{ Cassava flour } & Frequency & 7 & 11 & 2 & 4 & 5 & 1 & 1 & - & - \\
\hline & Percentage & 23.3 & 36.7 & 6.7 & 13.3 & 16.7 & 3.3 & 3.3 & - & - \\
\hline \multirow[t]{2}{*}{ Cassava Enjera } & Frequency & - & 5 & 7 & 7 & 5 & 3 & 2 & 1 & - \\
\hline & Percentage & - & 16.7 & 23.3 & 23.3 & 16.7 & 10 & 6.7 & 3.3 & - \\
\hline \multirow[t]{2}{*}{ Cassava cookies } & Frequency & 1 & 5 & 5 & 6 & 7 & 4 & 2 & - & \\
\hline & Percentage & 3.3 & 16.7 & 16.7 & 20 & 23.3 & 13.3 & 6.7 & - & - \\
\hline \multirow[t]{2}{*}{ Cassava Dabokollo } & Frequency & 2 & 7 & 4 & - & 3 & 3 & 4 & - & - \\
\hline & Percentage & 6.7 & 23.3 & 13.3 & - & 10 & 10 & 13.3 & - & - \\
\hline \multirow[t]{2}{*}{ Cassava Bread } & Frequency & 2 & 1 & 7 & - & 1 & 9 & 5 & 2 & 2 \\
\hline & Percentage & 6.7 & 3.3 & 23.3 & - & 3.3 & 30 & 16.7 & 6.7 & 6.7 \\
\hline \multirow[t]{2}{*}{ Cassava Anbasha } & Frequency & - & 1 & 1 & 4 & 4 & 5 & 10 & - & 5 \\
\hline & Percentage & - & 3.3 & 3.3 & 13.3 & 13.3 & 16.7 & 33.3 & - & 16.7 \\
\hline \multirow[t]{2}{*}{ Cassava Fosese } & Frequency & 6 & - & 4 & 2 & 2 & 2 & 4 & 4 & 6 \\
\hline & Percentage & 20 & - & 13.3 & 6.7 & 6.7 & 6.7 & 13.3 & 13.3 & 20 \\
\hline \multirow[t]{2}{*}{ Cassava Katkala } & Frequency & - & - & - & 1 & 1 & 3 & 2 & 10 & 14 \\
\hline & Percentage & & & & 3.3 & 3.3 & 10 & 6.7 & 43.3 & 46.7 \\
\hline \multirow[t]{2}{*}{ Cassava Borde } & Frequency & 12 & & & & 2 & & & 13 & 3 \\
\hline & Percentage & 40 & & & & 6.7 & & & 43.3 & 10 \\
\hline
\end{tabular}

Preference criteria of cassava food items and their preference rank: As depicted in (Table 6) above, about nine cassava food recipes were demonstrated to be preferred by respondent farmers. Having these criteria, $40 \%$ of respondents selected cassava borde, which is locally fermented and brewed from a combination of cassava and other crop grain, $23.3 \%$ of respondents selected cassava flour, and $20 \%$ of respondents selected Cassava fossose, which is a cultural food item used in the area. Based on these the sample respondents selected these three food items as a first-rank respectively. Also, in the second rank Cassava flour 36.7\%, 23.3\% and $16 \%$ of respondents selected Cassava Dabokollo, Cassava Enjera, and Cassava cookies respectively. About $23.3 \%$ 
selected Cassava Enjera and Cassava Bread; while 16.7\% of respondents selected Cassava cookies as a third rank respectively. However, cassava has low protein content, highly perishable after it is harvested; contains a higher number of cyanogenic glucosides and other toxins (Nweke et al., 2002).

Additionally, the small scale producers of injera have started producing injera from teff and cassava for maximizing their profit getting from the conventional teff injera. In this case, it is important to address the optimal level of the blending ratio of cassava and teff for the preparation of quality injera. In contrast, Cassava Katkala $46.7 \%$, of respondents, Cassava Anbasha 16.7\%, and Cassava Borde $10 \%$ were preferred as the ninth rank respectively. Since the majority of the inhabitants were Protestant Christianity, they were not able to use alcoholic drinks like katkala over those who practice traditional beliefs. These cassava food products had a great role in increasing the nutritional value and also to balance the consumption of teff, barley, and wheat availability and access in the study area specifically.

\section{CONCLUSION AND RECOMMENDATIONS}

Cassava is a multipurpose root crop used for the preparation of many food items in the study area. As related to traditional practices the new post-harvest handling of cassava minimizes listed problems by harvesting with care and chopping washed tuber with a pure knife in small pieces to be dried easy and timely. Also, it favors supplying to the market at the right time at a good price.

Farmers ranked the preference criteria; Postharvest handling of technology, Value addition, Processing of technology and Balanced diet as first, second, third and fourth respectively. About nine cassava food recipes were demonstrated to be preferred by respondent farmers. The majority of peoples of the woreda preferred cassava Borde, flour, and fossose as first, second and third respectively. So, it is recommended as the farmers of the study area should use the food products that were selected such as cassava flour, cassava fossose, cassava dabokolo, cassava enjera, and cassava bread. These should be demonstrated at large scale in the study area.

Acknowledgments: The authors would like to thank Southern Agricultural Research Institute (SARI), Jinka Agricultural Research Center (JARC) for material and financial support; providing demonstrating, facilitation of vehicles and technical backup. Our acknowledgment extends to the Agricultural Growth Program (AGP-II) for funding the pre-extension demonstration research activities in general and cassava post-harvest, handling management, and utilization activity in particular. Also, we thank the Semen Ari Woreda Agriculture and Natural Resource Management Office, Kebele administrators, farmers, and development agents (DAs) in the study without their active participation this work would have not been realized.

\section{REFERENCES}

Amsalu, N. (2006). Phenotypic Diversity of Cassava (Manihot esculenta Cranz.) in Ethiopia. Proceedings of the 12th Annual Conference of the CroP Science Society of Ethiopia, 22-24 May 2006, Addis Ababa, 12, 23-29.

Desalegn, T. (2007). Dynamics of agro-ecological knowledge in Amaro special Wereda, Southern Ethiopia, M.Sc. thesis, Haramaya University, Ethiopia.

Eddy, N., Udofia, P., \& Eyo, D. (2007). Sensory evaluation of wheat/ cassava composite bread and effect of label information on acceptance and preference. African Journal of Biotechnology, 6, 2415-2418.

El-Sharkawy, M.A. (2004). Cassava biology \& physiology. Plant Molecular Biology, 56, 481-501.

Falade, K. O., \& Akingbala, J. O. (2010). Utilization of cassava for food. Food Reviews International, 27, 51-83.

FAO (United Nations Food and Agricultural Organization), (2013). Save and Grow: Cassava a guide to sustainable production intensification. Found from www.fao.org/ag/save-and-grow/ and accessed on November 16, 2016.

FAO (Food and Agriculture Organization of the United Nations), (2014). Food Outlook. Biannual report on global food markets.

Food and Agricultural Organization (FAO) STAT, (2010). Statistical data base of the food and agricultural organization of the United Nations available at http://faostat.com.

Food and Agricultural Organization (FAO) STAT, (2013). Statistical data base of the food and agricultural organization of the United Nations accessed from http://faostat.org on August 10, 2015.

IITA, (2009). International Institute of Tropical Agriculture report online available at http://www.iita.org/cassava Oyo State, Nigeria. 
Haggblade, S., Djurfeldt, A. A., Nyirenda, D. B., Lodin, J. B., Brimer, L., Chiona, M., Chitundu, M., ChiwonaKarltun, L., Cuambe, C., \& Dolislager, M. (2012). Cassava commercialization in Southeastern Africa. Journal of Agribusiness in Developing and Emerging Economies, 2, 4-40.

Iyer, S., Mattinson, D. S., \& Fellman, J. K. (2010). Study of the early events leading to cassava root postharvest deterioration. Tropical Plant Biology, 3, 151-165.

Mudombi, C.R. (2010). An ex ante economic evaluation of genetically modified cassava in South Africa. M.Sc. (Agic) Dissertation University of Pretoria, South Africa.

Nweke, F., Spencer, D., \& Lynam, J. (2002). The Cassava Transformation: Africa's Best-Kept Secret. Michigan State University Press.

Opara, U. L. (2013). Perspective: the evolving dimensions and perspectives on food security what are the implications for postharvest technology research, policy and practice? International Journal of Postharvest Technology and Innovation, 3, 324-332.

Salcedo, A., DelValle, A., Sanchez, B., Ocasio, V., Ortiz, A.
Marquez, P., \& Siritunga, D. (2010). Comparative evaluation of physiological post-harvest root deterioration of 25 cassava (Manihot esculenta) accessions: visual vs. hydroxycoumarins fluorescent accumulation analysis. African Journal of Agricultural Research, 5, 3138-3144.

Sánchez, T., Dufour, D., Moreno, I. X., \& Ceballos, H. N. (2010). Comparison of pasting and gel stabilities of waxy and normal starches from potato, maize, and rice with those of a novel waxy cassava starch under thermal, chemical, and mechanical stress. Journal of Agricultural and Food Chemistry, 58, 5093-5099.

SNNPR (Southern Nationalities and Peoples Region, Bureau of Agriculture), (2014). Basic Agricultural Information Planning and programming Service, Hawassa, Ethiopia. Unpublished raw data.

Tadesse, T., Degu G., Shonga E., Mekonen S., Addis T., \& Yakob B. (2013). Current status, Potentials and challenges of Cassava production, processing, marketing and utilization: Evidence from Southern Ethiopia. Greener Journal of Agricultural Sciences, 3(4), 262-270.

Publisher's note: EScience Press remains neutral with regard to jurisdictional claims in published maps and institutional affiliations.

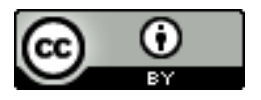

Open Access This article is licensed under a Creative Commons Attribution 4.0 International License, which permits use, sharing, adaptation, distribution and reproduction in any medium or format, as long as you give appropriate credit to the original author(s) and the source, provide a link to the Creative Commons license and indicate if changes were made. The images or other third-party material in this article are included in the article's Creative Commons license, unless indicated otherwise in a credit line to the material. If material is not included in the article's Creative Commons license and your intended use is not permitted by statutory regulation or exceeds the permitted use, you will need to obtain permission directly from the copyright holder. To view a copy of this license, visit http://creativecommons.org/licenses/by/4.0/.

(C) The Author(s) 2019. 